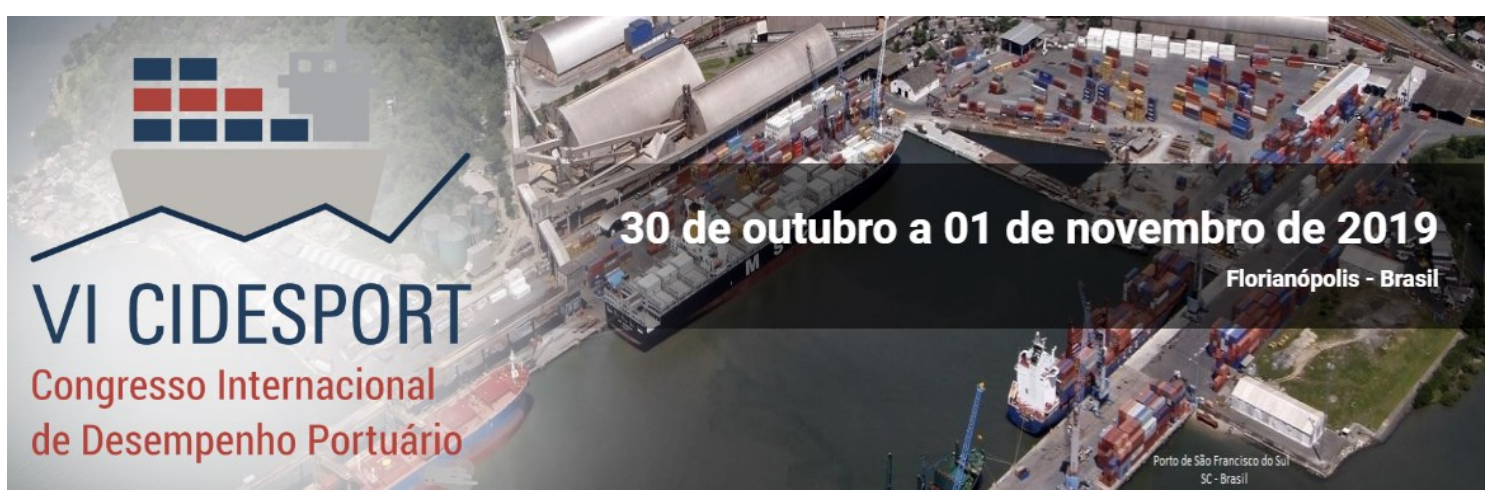

\title{
AGENDA AMBIENTAL PORTUÁRIA COMO PROCESSO DE NEGOCIAÇÃO: O CASO DO PORTO DE PELOTAS - SISTEMA HIDROVIÁRIO LAGOA DOS PATOS - CANAL SÃO GONÇALO
}

\author{
Tanise Felix da Luz Godinho \\ Universidade Federal do Rio Grande \\ Icaro Cunha \\ Universidade Federal do Rio Grande
}

Resumo: A Agenda Ambiental Portuária Local pode ser resumida como um compromisso entre os diversos segmentos interessados a gestão de um porto, que através de um gesto de adesão e de partilha de responsabilidades, é capaz de promover o desenvolvimento sustentável, contemplando as dimensões: ambiental, social e econômica. Esta agenda se ampara nas perspectivas do Gerenciamento Costeiro Integrado. Este estudo pretendeu elaborar uma pauta para a discussão futura da Agenda Ambiental Local para o Porto de Pelotas, por meio do estabelecimento de uma Zona de Possíveis Acordos (ZOPA). Para que isso fosse possível, foram realizadas entrevistas com vinte atores - os stakeholders, a metodologia adotada para a avaliação seguiu as orientações da abordagem de ganhos mútuos - Método Harvard de Negociação, o qual indica que deve-se focar em interesses e não em posições, com isso sondou-se os interesses explícitos e subjacentes de cada ator entrevistado, sendo possível de se visualizar um total de 35 tópicos diferentes de interesses entre todas as entrevistas, os quais foram cruzados a fim de se encontrar convergências, sendo encontrados assim 22 tópicos que possuem alguma convergência e que consistem na Zona de Possíveis Acordos (ZOPA). Os resultados trazem uma visão otimista quanto aos compromissos que podem ser assumidos entre a Autoridade Portuária e os stakeholders do porto - uma vez que estes demonstram, entre outros interesses, que gostariam de ver melhoria na qualidade dos recursos hídricos locais e de ter uma maior interação com a gestão do porto para que juntos possam ir à busca de ganhos mútuos.

Palavras-chave: Agenda Ambiental Portuária Local. Conflitos Socioambientais. Abordagem de Ganhos Mútuos. Método Harvard de Negociação. Zona de Possíveis Acordos.

\section{INTRODUÇÃO}

No município de Pelotas, no estado do Rio Grande do Sul, extremo sul do Brasil, à margem denominada esquerda ou norte do Canal São Gonçalo, o qual se conecta com a Lagoa dos Patos (maior lagoa do país, une-se ao Oceano Atlântico na cidade de Rio Grande, por esse motivo também denomina-se Laguna dos Patos) e com a Lagoa Mirim (segunda maior lagoa do país, na qual parte se encontra em

${ }^{*}$ A revisão gramatical, ortográfica, ABNT ou APA foi realizada pelos autores. 


\section{CIDESPORT/2019}

Congresso Internacional

de Desempenho Portuário

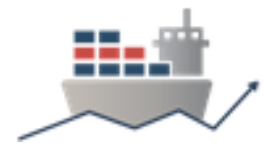

território uruguaio), localiza-se o Porto de Pelotas, que é um dos portos públicos integrantes do Sistema Hidroviário da Bacia da Lagoa dos Patos.

A autorização para a construção de um porto na cidade de Pelotas foi concedida no ano de 1928, o início das obras se deu em 1933, porém um acidente que ocorreu durante a construção retardou a abertura do porto, que somente entrou em operação no ano de 1940 (Campêlo e Duhá, 2009). De acordo com LabTrans (2013), o Porto de Pelotas ocupa uma área de aproximadamente 749.054 metros quadrados, possui 500 metros de cais acostável e é naturalmente abrigado por se situar na margem esquerda (ou norte) do Canal São Gonçalo (Figura 1).

Figura 1: Localização do Porto de Pelotas.

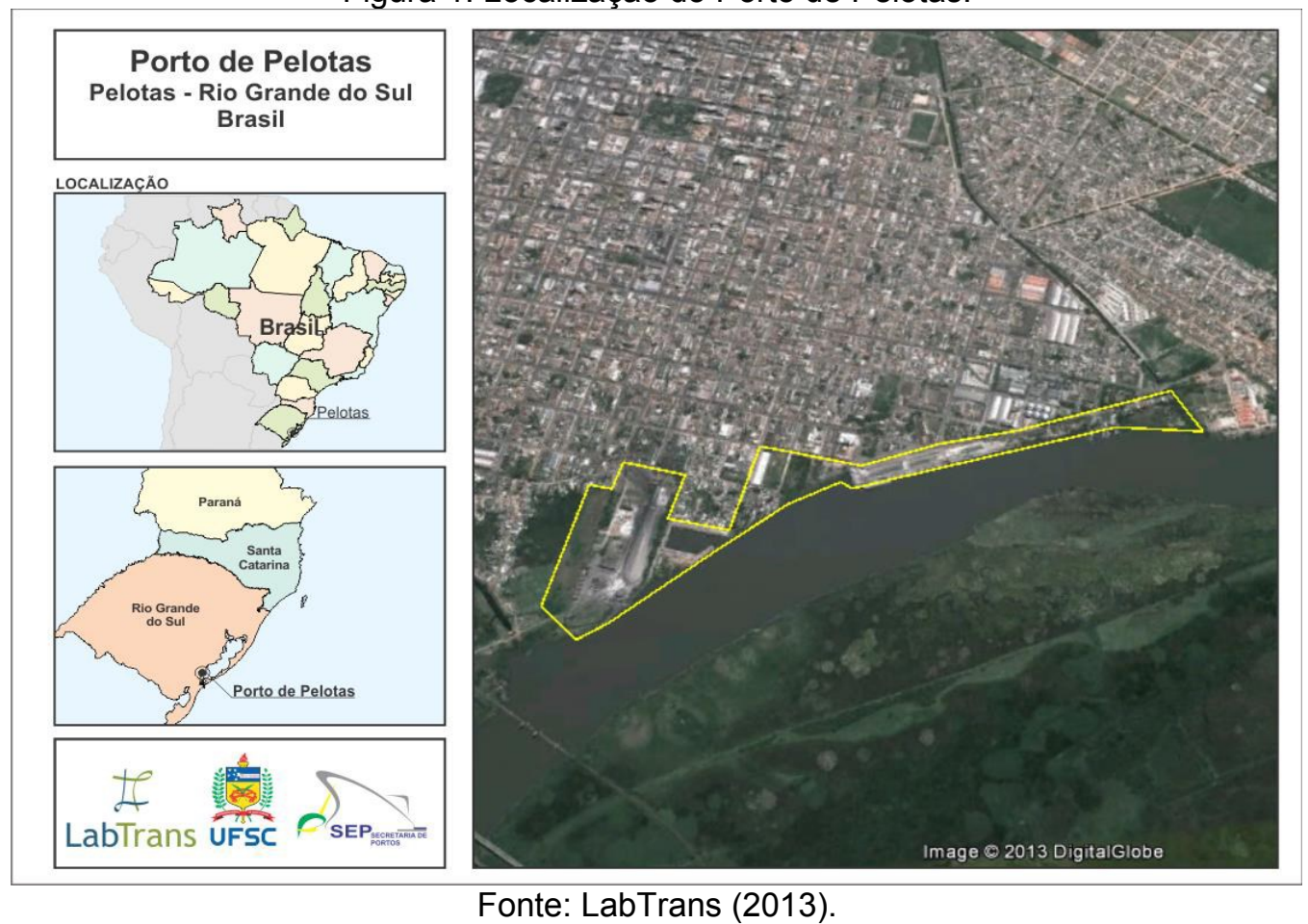

O Porto de Pelotas encontra-se em expansão atualmente, resultado de um momento especial no que se refere à sua movimentação econômica. Por muitos anos, o porto esteve em atividade com uma pequena operadora (que hoje não opera mais) e com um número extremamente baixo de carregamento, porém, em novembro de 2015 foi firmado um Contrato de Uso Temporário (CUT) entre SPH (atual SUPRG) e CMPC Celulose Riograndense, trazendo uma nova configuração ao ambiente portuário, através da instalação de um Terminal de Toras de Madeira.

A nova operação, que é também a de maior expressão, está por conta da Sagres Operações Portuárias (na época, Sagres Agenciamentos Marítimos), que está transportando toras de madeira de eucalipto para a empresa CMPC Celulose Riograndense desde outubro de 2016. Estas empresas qualificaram a infraestrutura do porto público e revitalizaram a orla portuária de Pelotas. Conforme Mazza (2016), a logística prevista na nova operação tem foco no incremento da hidrovia gaúcha, mudando positivamente o cenário local com a criação de 800 empregos diretos e 2 mil indiretos, através da união entre Celulose Riograndense e Sagres Agenciamentos Marítimos. As empresas deram prioridade às contratações de mão de obra da região.

As toras são oriundas de 14 municípios da zona sul do estado e chegam ao Porto de Pelotas através de caminhões. No porto elas são carregadas em barcaças 


\section{CIDESPORT/2019}

Congresso Internacional

de Desempenho Portuário

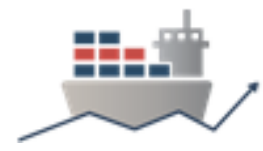

(chatas) e seguem pela hidrovia, por navegação interior, durante o período de 18 horas de viagem, tendo como destino a CMPC, fábrica de celulose e papel com sede em Guaíba - distante 237 quilômetros por rodovia. Na fábrica a pasta de celulose é extraída das toras de eucalipto e parte desta pasta retorna pela hidrovia através das mesmas barcaças e agora tendo como destino o Porto de Rio Grande, local onde é encaminhada, através da navegação de longo curso, para a exportação. De acordo com Magalhães (2016), cada uma dessas barcaças comporta a carga de 80 a 90 caminhões bitrens (2.500 toneladas). Conforme Ross (2016), a previsão é que em seu ápice de operação, o número de barcaças carregadas no porto possa chegar a seis por dia. E com essa operação o porto passa a transportar 1,6 milhão de toneladas/ano, sendo que a média anterior era de 400 mil toneladas/ano.

A exemplo do que ocorre em muitas cidades costeiras do Brasil e do mundo, Pelotas também sofre com fatores de pressão sobre os ecossistemas costeiros, há degradação da qualidade da água por lançamento de esgoto doméstico e industrial grande parte destes in natura, como também, por introdução de agrotóxicos decorrentes das grandes áreas de cultivos - tais como arroz e soja, o que ocasiona ainda a contaminação dos solos e banhados (termo regional para denominar uma área úmida equivalente ao brejo), ambientes estes que contam com uma rica flora e fauna, são inúmeras as espécies de peixes, aves, anfíbios, répteis, mamíferos e também animais invertebrados, inclusive muitas destas espécies ameaçadas de extinção, que habitam os banhados. Ocorre também ocupação irregular, descarte inapropriado de resíduos sólidos urbanos, entre outros fatores que contribuem para a degradação da zona costeira.

Os portos do Sistema Hidroviário da Bacia da Lagoa dos Patos estão iniciando uma trajetória de Gestão Ambiental, a exemplo do Porto de Pelotas, onde essa trajetória é motivada pelo novo contexto econômico em que ele se encontra. Para que isso fosse possível, o Porto de Pelotas buscou a sua Licença de Operação (LO), junto ao órgão ambiental do estado do Rio Grande do Sul - a FEPAM (Fundação Estadual de Proteção Ambiental Henrique Luiz Roessler), sendo a primeira licença ambiental para um porto emitida pelo referido órgão. Esta Licença de Operação - LO No 8162/2015 - DL - foi emitida pela FEPAM em 03 de dezembro de 2015 e está vigente até a data de 03 de dezembro de 2019.

Esse aproveitamento do sistema hidroviário é de extrema importância, devido à grande vantagem que o modal possui por ser mais sustentável do que outros modais de transportes - como rodovias e ferrovias, em especial porque consome menos combustível fóssil e emite menos poluente.

\section{REFERENCIAL TEÓRICO}

Embora seja o sistema hidroviário o modal mais sustentável de transporte, a atividade portuária possui um grande e diversificado poder de alteração sobre as condições ambientais, pois funciona como uma infraestrutura consolidadora da dinâmica territorial (Cunha et al., 2014). Por ser uma atividade que se desenvolve em ambientes sensíveis, possui elevado potencial de geração de impactos ambientais (MMA, 2014).

Ao mesmo tempo, a área costeira possui ecossistemas valiosos de grande produtividade e biodiversidade, por esse motivo a área é geralmente de grande valor para a população humana, a qual procura se instalar, usar e desfrutar dos recursos costeiros e marítimos do local. A zona costeira é estratégica para a economia, pois essa área oferece a base para todas as atividades humanas (Cicin-Sain e Knecht, 


\section{CIDESPORT/2019}

Congresso Internacional

de Desempenho Portuário

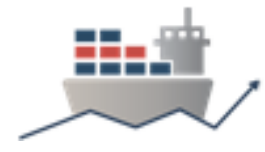

1998). Atividades estas como: transporte de cargas, pesca, recreação, turismo, translado de pessoas, indústrias, agricultura, desenvolvimento mineral, entre outras atividades. Conforme Diegues (2001), a presença dessa grande potencialidade para inúmeras atividades humanas, muitas vezes em espaços reduzidos, leva a conflitos de uso. Polette e Asmus (2015) relatam que estas atividades econômicas nem sempre ocorrem de forma ajustada ao seu contexto ecossistêmico, gerando efeitos socioambientais indesejados e conflitos de uso.

Desse modo, torna-se evidente a necessidade de que os portos adotem medidas de gestão ambiental, que também incorporem mecanismos de negociação de conflitos para esta gestão, por meio de processos que visam o Gerenciamento Costeiro Integrado.

Para Cicin-Sain e Knecht (1998), o Gerenciamento Costeiro Integrado pode ser definido como um processo contínuo e dinâmico, no qual decisões são tomadas visando o uso sustentável, desenvolvimento e proteção das áreas marinhas e costeiras e de seus recursos. Processo este, que pode se desenvolver de diferentes formas, conforme as particularidades, condições físicas, socioeconômicas, culturais e políticas das diferentes nações.

A gestão ambiental portuária constitui-se pela implementação contínua de um conjunto de processos, procedimentos, tecnologias ou métodos operacionais utilizados para eliminar ou controlar fontes de pressão ou de impactos ambientais originadas pelo desenvolvimento e operação dos portos (MMA, 2016).

CIRM (1998) relata que as conquistas ambientais na área portuária dependem, em grande parte, do estabelecimento e implantação de políticas específicas para o setor, como a Agenda Ambiental Portuária (AAP). Esta agenda é uma política federal para o setor portuário, que foi promulgada pela Resolução CIRM n ${ }^{\circ} 006$, de 02 de dezembro de 1998. A criação da agenda resultou em uma inovação para esse setor, que até então, não considerava os aspectos ambientais em seus procedimentos de gestão.

Segundo MMA (2016), a Agenda Ambiental Portuária expressa às diretrizes de promoção e melhoria da qualidade ambiental dos portos, com vistas à sustentabilidade. Estas diretrizes provêm da legislação geral, instruções normativas e resoluções que regram a política de gerenciamento costeiro, como também, de convenções e acordos internacionais ratificados pelo Brasil. E agrega ainda, iniciativas voluntárias de certificação ambiental. Conforme Cunha et al. (2014), a construção desta agenda é um exercício de reconhecimento mútuo entre diferentes usuários de recursos comuns estratégicos ao desenvolvimento. Sendo um passo fundador para construir relações de responsabilidade, que possam amparar a cooperação para superar dificuldades, que necessariamente ocorrem diante do tamanho do porto no território, na cidade e na mudança do espaço litoral.

A Agenda Ambiental Portuária se complementa por dois segmentos - Agenda Ambiental Local e Agenda Ambiental Institucional, conforme Figura 2. 


\section{CIDESPORT/2019}

Congresso Internacional

de Desempenho Portuário

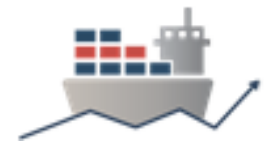

Figura 2: Agendas Ambientais Portuárias e suas esferas de atuação.

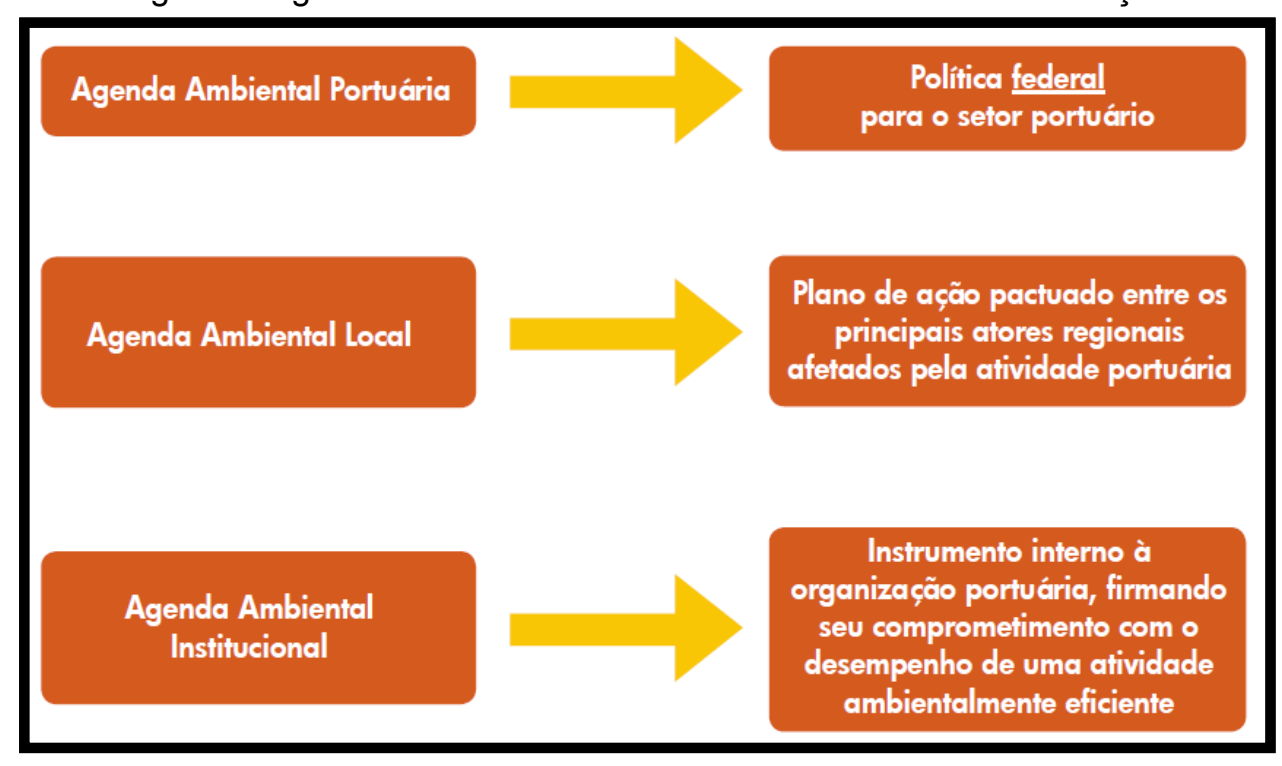

Fonte: ANTAQ (2011).

A Agenda Ambiental Local, foco da presente pesquisa, consiste em um instrumento de planejamento e articulação das Autoridades Portuárias e demais responsáveis por instalações portuárias com os agentes intervenientes ou afetados pela atividade - os stakeholders, tais como governos estaduais e municipais, agentes reguladores e fiscalizadores, agentes regulados, comunidades portuárias, comunidade local, prestadores de serviços, entre outros setores. Esta agenda incorpora os aspectos regionais nas discussões sobre o meio ambiente portuário, contemplando os compromissos da Autoridade Portuária e demais agentes com a qualidade dos recursos naturais, com a saúde e segurança ocupacionais, com as questões sanitárias, de segurança institucional, considerando ainda a capacitação dos agentes intervenientes para ações de valorização dos ambientes onde a atividade esteja presente (ANTAQ, 2011).

Freeman (1984, p. 46) caracteriza os stakeholders como "qualquer grupo ou indivíduo que pode afetar ou ser afetado pela realização dos objetivos da organização". Vinha (2010) incorpora ao termo stakeholder, além dos membros da cadeia produtiva, as comunidades, as ONG's, o setor público, as firmas e indivíduos formadores de opinião, como também, as vítimas reais e potenciais dos impactos ambientais das atividades da organização.

Já a Agenda Ambiental Institucional deve ser elaborada pela própria Autoridade Portuária, firmando seu compromisso com o desenvolvimento de uma atividade em harmonia com o meio ambiente. Nela são estabelecidas a missão, a política ambiental, os objetivos estratégicos e específicos, as metas, os planos e os programas da organização. As ações dessa agenda devem envolver todos os setores e trabalhadores do porto ou instalações portuárias fora dele, visando à conscientização ambiental e o envolvimento dos agentes atuantes na área. A implementação desta agenda conduz aos seguintes resultados: melhoria da imagem da organização, maior eficiência na prestação dos serviços, redução de custos sociais, aumento da competitividade, atração de novos mercados consumidores, redução de riscos ambientais, aumento da confiabilidade da organização e melhoria da qualidade do ambiente interno da organização (ANTAQ, 2011). 


\section{CIDESPORT/2019}

Congresso Internacional

de Desempenho Portuário

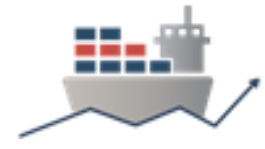

Conforme Cunha (2008), a Agenda Ambiental Local abre oportunidade para que os portos se insiram no jogo de negociação de conflitos, em que os objetivos de melhoria da qualidade ambiental e as responsabilidades sejam compartilhados entre diversos atores regionais, recuperando a discussão das estratégias socioambientais corporativas, a exemplo da busca de legitimidade para as organizações através de negociações com stakeholders. De acordo com Little (2001), os conflitos socioambientais podem ser compreendidos como disputas entre grupos sociais derivadas dos diversos tipos de relações por eles mantidas com seu meio natural. Ocorrem conflitos pelo controle dos recursos naturais, conflitos derivados dos impactos ambientais e sociais decorrentes de determinados usos, e também aqueles ligados aos usos e apropriações dos conhecimentos ambientais.

A negociação se apresenta por meio da construção de melhor(es) alternativa(s) para cada um dos interlocutores, implicando na eventual conciliação de interesses, muitas vezes, conflitantes. Nessa construção, há interação de saberes referentes ao escopo do que será negociado, traduzindo em uma prática de alocações de decisões (Granja, 2012). O método conhecido como abordagem dos ganhos mútuos para resolução de disputas é um conjunto de propostas de estratégias que facilitam a construção de entendimentos em situações de conflito envolvendo muitos atores, como são tipicamente os conflitos socioambientais (Cunha, 2008). O modelo se baseia na justiça e na democracia, com o objetivo de garantir a confiança das partes contando com alguma cooperação entre elas, buscando assim a construção de alternativas em conjunto. O foco é nos interesses, não nas posições dos interlocutores, proporcionando flexibilidade para obter acordos e construir relações de longo prazo (Granja, 2012).

Esse mecanismo de negociação de conflitos é consagrado como Método Harvard de Negociação. O Programa de Negociação de Harvard - "Program on Negotiation" (PON) é um consórcio universitário entre a Universidade de Harvard, o Instituto de Tecnologia de Massachusetts e a Universidade Tufts, no qual os pesquisadores se dedicam ao desenvolvimento de teoria e prática de negociação e resolução de disputas (PON, 2017). O método vem sendo utilizado por organizações conceituadas em resolução de conflitos, como o Conflict Management Inc. (CMI), o Conflict Management Group. (CMG) e o Consensus Building Institute (CBI).

De acordo com Fisher, Ury e Patton (2014), o Programa de Negociação de Harvard desenvolveu uma alternativa à barganha posicional, um método de negociação explicitamente concebido para produzir resultados sensatos, de forma eficiente e amigável, baseada em princípios. Método esse que pode ser resumido a quatro pontos básicos: pessoas, interesses, opções e critérios.

Conforme Fisher e Ertel (1997), a negociação não passa por cima das diferenças, mas reconhece que estas podem ajudar a fazer com que cada um dos envolvidos acabe em uma situação melhor do que estaria sem um acordo. Desse modo, as melhores negociações são aquelas em que uma série de opções possíveis tenham sido exploradas, pois quanto maior o número de opções, maior será a chance de que uma delas efetivamente concilie os diferentes interesses das partes.

Para chegar a tal entendimento, deve-se primeiramente identificar as partes relevantes, posteriormente esclarecer os interesses e sondar os interesses subjacentes, após, deve-se criar opções a fim de atender os interesses, para que seja possível então de se encontrar meios de maximizar ganhos conjuntos (Fisher e Ertel, 1997). Esse esquema se apresenta por meio da elaboração de uma Zona de Possíveis Acordos (ZOPA), um campo em torno do qual se pode buscar construir cooperação. 


\section{CIDESPORT/2019}

Congresso Internacional

de Desempenho Portuário

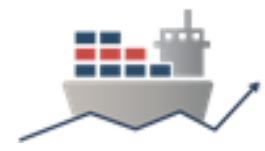

Diante do disposto e tendo como objeto de estudo o Porto de Pelotas e seu entorno, o presente artigo apresenta resultados de uma pesquisa que buscou auxiliar na qualificação da gestão ambiental do Porto de Pelotas, por meio da indicação de tópicos, através da elaboração de uma Zona de Possíveis Acordos (ZOPA), que permitirá subsidiar a construção de uma pauta para a discussão futura da Agenda Ambiental Local para o referido porto.

\section{PROCEDIMENTOS METODOLÓGICOS}

Adotou-se para a realização da presente pesquisa a abordagem qualitativa, uma vez que esta trabalha com um universo de significados, motivos, aspirações, crenças, valores e atitudes, que correspondem a um espaço mais profundo das relações, dos processos, dos fenômenos e por isso que não podem ser reduzidos à operacionalização de variáveis (Minayo et al., 2002). Foi feita uma pesquisa exploratória sobre a hidrovia, que através de um estudo focado no Porto de Pelotas e seu entorno, gerou elementos capazes de ajudar a compreender o conjunto como um todo. Conforme Gil (2008, p. 27), "as pesquisas exploratórias são desenvolvidas com o objetivo de proporcionar visão geral, de tipo aproximativo, acerca de determinado fato. Este tipo de pesquisa é realizado especialmente quando o tema escolhido é pouco explorado".

A metodologia adotada para a obtenção de dados consistiu na realização de entrevistas com os atores - os stakeholders - que possuem influência ou que são influenciados pela movimentação de cargas no Porto de Pelotas e/ou pelo uso do sistema hidroviário. E contou ainda, com o apoio de levantamento de dados por meio de consultas ao noticiário local e revisão conceitual documental - a exemplo da Agenda Ambiental Local do Porto de Santos, única agenda portuária local existente no país até o momento.

A técnica utilizada para a realização das entrevistas foi a de entrevista estruturada. De acordo com Gil (2008, p. 113), "a entrevista estruturada desenvolvese a partir de uma relação fixa de perguntas, cuja ordem e redação permanece invariável para todos os entrevistados, que geralmente são em grande número". O formulário contou com 25 perguntas que foram preparadas com a finalidade de caracterizar a situação dos atores (necessidades, interesses e posições) em relação ao ambiente portuário. Este foi elaborado de modo que as perguntas fossem feitas de forma cruzada, sendo que mais de uma pergunta procurou apurar algum tipo de fenômeno de resposta com o mesmo objetivo. Assim, buscou-se por outro ângulo a subjetividade das respostas.

Com relação à seleção dos atores, preliminarmente foram selecionados $15 \mathrm{a}$ serem entrevistados, o levantamento destes foi possível de ser realizado a partir de uma conversa que antecedeu a pesquisa, junto a Autoridade Portuária de Pelotas, como também, através da observação do espaço em campo e de consultas ao noticiário local. A estratégia de comunicação adotada para o estabelecimento de contato ocasionou-se por meio de visita in loco para a apresentação do projeto, como também, contato via telefone, e-mail e rede social (Facebook).

Além das entrevistas realizadas com os atores preliminarmente selecionados, foram realizadas entrevistas também com outros atores que apareceram ao longo da pesquisa. E estes atores que apareceram ao longo da pesquisa, foram indicados por atores preliminarmente selecionados, o que sugere o uso da metodologia Bola de Neve. Conforme Baldin e Munhoz (2011), a técnica metodológica Bola de Neve é um modo de amostra não probabilística utilizada em pesquisas sociais, onde os 


\section{CIDESPORT/2019}

Congresso Internacional

de Desempenho Portuário

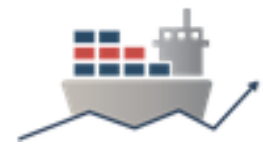

participantes iniciais de um estudo indicam novos participantes, que por sua vez indicam novos participantes e assim sucessivamente, até que seja alcançado o objetivo proposto, o chamado Ponto de Saturação. Este ponto é atingido quando os novos entrevistados passam a repetir os conteúdos já obtidos em entrevistas anteriores, sem acrescentar novas informações relevantes à pesquisa.

Desse modo, foi possível de se estabelecer contato e realizar entrevistas com um total de 20 atores, tais como: Autoridade Portuária; Empresa operadora portuária; Governo local; Praticagem; Conservação governamental; Conservação não governamental; Comitê de Bacia; Pesquisadores; Entidades representativas da Pesca, da Náutica e da Comunidade local.

Contando com o consentimento prévio dos entrevistados, registraram-se áudios das entrevistas por meio de um dispositivo de gravação, para que após a conclusão destas fosse possível realizar as transcrições. Foram construídos quadros de análise a fim de avaliar os resultados das entrevistas e chegar ao reconhecimento da Zona de Possíveis Acordos (ZOPA). Para tal análise trabalhou-se com a orientação da metodologia de negociação de conflitos da abordagem de ganhos mútuos Método Harvard de Negociação. Essa metodologia indica que deve-se focar em interesses, não em posições e que depois de sondar os interesses explícitos e subjacentes de cada setor, se passe para a visualização de um conjunto de pontos de convergências, que consiste na Zona de Possíveis Acordos (ZOPA), a qual sugere uma pauta base para a discussão futura da Agenda Ambiental Local para o Porto de Pelotas.

\section{RESULTADOS E DISCUSSÕES}

Através da análise das entrevistas, seguindo como orientação a abordagem de ganhos mútuos (Método Harvard de Negociação), foi possível sondar os interesses explícitos e subjacentes de cada ator entrevistado. Da análise destes interesses sondados a partir da visão dos 20 atores entrevistados, foi possível de se visualizar um total de 35 tópicos diferentes de interesses entre todos os atores, os quais foram cruzados a fim de se encontrar convergências, os campos para a construção de entendimentos, sendo encontrados assim 22 tópicos que possuem alguma convergência (Quadro 1) e que consiste na Zona de Possíveis Acordos (ZOPA) que indica a pauta base para a discussão futura da Agenda Ambiental Local para o Porto de Pelotas, sendo os tópicos de maior convergências os que possuem real potencial para reunir as forças para a possível discussão e criação da agenda, por esse motivo estes resultados foram os escolhidos para a discussão.

Quadro 1: Zona de Possíveis Acordos encontrada na análise das entrevistas.

\begin{tabular}{|c|c|}
\hline $\begin{array}{c}\text { TÓPICOS DE INTERESSES EXPLÍCITOS E SUBJACENTES } \\
\text { ENCONTRADOS NA ANÁLISE DAS ENTREVISTAS: }\end{array}$ & $\begin{array}{c}N^{\circ} \text { DE ATORES QUE } \\
\text { CONVERGEM NESSE }\end{array}$ \\
\hline Melhoria da qualidade dos recursos hídricos & 19 atores \\
\hline Programas de gestão ambiental portuária & 18 atores \\
\hline Programas de educação ambiental & 13 atores \\
\hline Envolvimento do porto com a cidade elou seu entorno & 12 atores \\
\hline Planejamento da expansão portuária & 11 atores \\
\hline Melhoria na sinalização hidroviária & 10 atores \\
\hline Gerenciamento ambiental da dragagem & 8 atores \\
\hline Manutenção da profundidade da hidrovia & 7 atores \\
\hline Disposição adequada do material dragado & 6 atores \\
\hline Gestão ambiental pública & 6 atores \\
\hline
\end{tabular}




\section{CIDESPORT/2019}

Congresso Internacional

de Desempenho Portuário

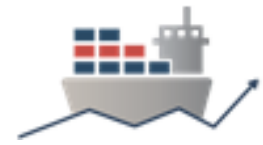

\begin{tabular}{|c|c|}
\hline Uso hidroviário para transporte de pessoas & 6 atores \\
\hline Plano de controle de emergência & 5 atores \\
\hline Programas de gestão ambiental empresarial & 4 atores \\
\hline Utilização do valor cultural do porto & 4 atores \\
\hline Serviço de apoio a emergência & 3 atores \\
\hline Troca de experiências/trabalho em equipe & 3 atores \\
\hline Maior articulação do porto com a própria atividade & 3 atores \\
\hline Melhoria na segurança da região & 3 atores \\
\hline Gerenciamento da água de lastro & 2 atores \\
\hline Sistema de informação sobre monitoramento ambiental & 2 atores \\
\hline Local no porto destinado à própria atividade & 2 atores \\
\hline Ter mais movimento e investimento no porto & 2 atores \\
\hline
\end{tabular}

Fonte: Elaborado pelos autores.

Os resultados de maior expressão decorrentes da análise das 20 entrevistas são os interesses pela "melhoria da qualidade dos recursos hídricos" (convergiram 19 atores) e "programas de gestão ambiental portuária" (convergiram 18 atores). Estes interesses foram expressos pelos atores quando, entre outras perguntas, questionouse quanto à visão sobre a qualidade atual das águas do Sistema Hidroviário Lagoa dos Patos - Canal São Gonçalo, sobre a atual influência do Porto de Pelotas nestas águas e também sobre a percepção do cuidado com os recursos hídricos em relação ao porto. Os resultados mostram o quanto estes atores estão inteirados com a situação do ambiente onde residem, uma vez que se demonstram preocupados com o precário saneamento da cidade e com o uso de agrotóxicos na bacia hidrográfica. Quanto à influência do porto nas águas, a maioria relatou que ele pouco altera, que não vêem problemas decorrentes da atividade portuária hoje, porém entendem que se faz necessário o cuidado do ambiente por sua parte, através da elaboração de programas de gestão. Fatos que podem ser observados, por exemplo, nas seguintes declarações:

"Super poluídas, por causa do lixo, do esgoto e dos agrotóxicos das granjas de arroz. Vocês não imaginam o que tem de sacola, fralda, plástico e isso nos atrapalha muito na nossa atividade [...]. Acho que o porto não deixa nem mais limpo e nem mais sujo [...]. O porto deve ter programas voltados para o meio ambiente [...]". PESCADOR

"Bastante contaminadas, o esgoto da cidade vai para o Canal São Gonçalo e para a Praia do Laranjal. Os agrotóxicos que colocam na soja e no arroz vão para a bacia hidrográfica. Os pescadores têm relatado que a vegetação costeira está morrendo nas margens da lagoa, o que pode ter relação com os agrotóxicos [...]. No momento o porto pouco causa influência, já que ele pouco movimenta. A sujeira aparece quando há dragagem [...]. Devido ao fato de ser uma atividade de alto risco deveria cuidar. Acredito que vai cuidar somente se alguém obrigar monitorar [...]". PESQUISADOR

"Está com índice muito alto de poluição, pois há deseducação do povo que joga muito lixo, plantações com agrotóxicos, esgotos mal administrados [...]. O porto tem que saber o que está transportando, deve ter o controle das embarcações, ver se largam coisas na lagoa, analisar o impacto dessas embarcações no ecossistema, ver se atrapalha o sistema pesqueiro, tem que analisar a própria 


\section{CIDESPORT/2019}

Congresso Internacional

de Desempenho Portuário

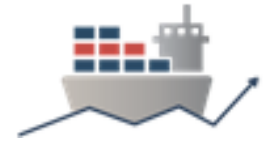

infraestrutura portuária, ver se ele mesmo por parte da administração não está despejando nada no canal [...]". VELEJADOR

"Estão poluídas faz tempo, mas visivelmente não dá para perceber. Chegaram as lavouras de arroz e causaram muitos danos, eu comecei a observar a poluição principalmente por causa da fauna que começou a desaparecer e começaram aparecer intoxicações, alergias, um monte de coisa que a gente não tinha antes e passamos a ter. Somando a isso tem o esgoto da cidade [...]. A cidade o porto já está cuidando agora, quanto à água, através de programas de monitoramento, pois a água é inclusive para eles mesmos, ela é um bem comum a todos". AGENTE COMUNITÁRIA

"Horrorosas, o município é responsável pelo saneamento e a gente discute muito isso, nós temos índices que demonstram que a gente joga in natura todo o nosso esgoto ou perto de $90 \%$ do que produzimos, tem que ter uma decisão política e econômica mais forte sobre a questão de saneamento da nossa região [...]. 0 porto tem mínima relação com isso, o maior problema não é o transporte marítimo, quem mais danifica somos nós os municípios quando largam os dejetos, aí precisa se ter essa visão ampliada com a sociedade [...]. O porto tem que provar que é sustentável, tem que olhar para a sua poligonal portuária, para os seus terminais. Nós temos que desenhar a poligonal portuária com mais precisão, precisamos dividir bem esses espaços. Ele possui uma responsabilidade enorme e acredito que o volume de regras que hoje foram colocadas ajudam regular isso [...]". GOVERNO LOCAL

"Os dados mostram que a quantidade de coliformes fecais está muito alta, o exprefeito nos narrou que $80 \%$ do esgoto de Pelotas não é tratado e é lançado no São Gonçalo e o São Gonçalo lança na Lagoa dos Patos. A gente fez um mapeamento das estações de tratamento de esgoto em Pelotas, aí se viu que só a do Laranjal funciona e que mesmo assim atende um número muito pequeno de residências, então aquele $80 \%$ de esgoto não tratado é um cenário muito otimista, talvez no máximo aí $2 \%$ - 3\% sejam efetivamente tratados, quase que $100 \%$ do esgoto de Pelotas vai in natura [...]. E em termos de São Gonçalo tem principalmente o veneno das granjas que escoam para o canal [...]. Diante da quantidade de esgoto da cidade o porto é ínfimo, até pelo baixo movimento que ele tem hoje, eu tenho a impressão que o impacto do porto frente a todo o resto é mínimo, não que isso sirva para diminuir a responsabilidade do porto, ele deve ter um bom programa de gestão ambiental que minimize os impactos, tanto preventivamente como corretivamente, em termos de acidentes que acontecem, tem que ter um plano de contingências para lidar com acidentes e evitar o miudinho do dia a dia, como a água de lastro e a limpeza de navios no porto, ainda mais o Porto de Pelotas que tá confinado no São Gonçalo junto de uma zona urbana ampla, aqui o impacto de um problema ambiental relacionado com o porto vai afetar mais e estar mais concentrado". CONSERVAÇÃO NÃOGOVERNAMENTAL

Os atores também demonstraram grandes convergências de interesses pela criação de "programas de educação ambiental" (convergiram 13 atores), "envolvimento do porto com a cidade e/ou seu entorno" (convergiram 12 atores) e "planejamento da expansão portuária" (convergiram 11 atores). Tais interesses foram 


\section{CIDESPORT/2019}

Congresso Internacional

de Desempenho Portuário

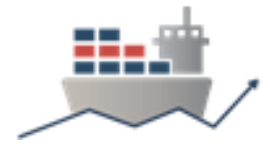

demonstrados quando, entre outros questionamentos, perguntou-se sobre a percepção quanto ao cuidado com os recursos hídricos em relação à própria atividade, o cuidado com a cidade em relação ao porto e a possibilidade de expansão da atividade portuária devido ao novo contexto econômico em que o porto se encontra. Os resultados mostram que além dos atores da área da conservação, muitos outros reconhecem a importância da educação ambiental e percebem que é através da mesma que se pode ir à busca da qualidade do ambiente no qual residem, alguns atores sugerem inclusive a criação de programas de educação ambiental em parceria com o porto. Os resultados também trazem uma visão otimista quanto aos compromissos que podem ser assumidos entre a Autoridade Portuária e os stakeholders do porto - uma vez que estes atores demonstram que gostariam de ter uma maior interação com a gestão do porto para que juntos possam ir à busca de melhorias que visam os ganhos mútuos. Há certa preocupação por parte de alguns atores com relação à possível expansão portuária. Tais fatos podem ser verificados, por exemplo, nas seguintes declarações:

"Pela a minha atividade econômica que é a produção de arroz, se tem muitíssimas ações a serem tomadas, muitas vem sendo tomadas paulatinamente, pois eu atuo também como extensionista e no processo de extensão, de educação, a gente tenta implementar a consciência, porque a agricultura tem uma tremenda capacidade de modificar em termos de área, ela atua em uma superfície bastante grande e essa atividade agropecuária ela pode ser degradante ou curativa, preventiva, existem vários mecanismos que a gente tem estabelecido para estimular esse tipo de adoção de princípios e de tecnologias, como exemplo, o selo ambiental que estabelece um sistema de princípios básicos, de boas práticas e dentro dessa conversa de boas práticas se faz um acompanhamento através do Comitê Local em cada escritório, então tem que ter um processo educativo e um processo de fiscalização, acreditando eu que o processo de conscientização é mais eficiente, mas não se abre mão de eventualmente fazer uma punição [...]. O porto tem que adotar medidas educativas, protetivas, de licenciamento e assim por diante. Deve cuidar da cidade, toda a ação promove uma reação, então a grande questão é ter inteligência de concertação dos interesses, porque normalmente quando as partes se juntam para propor soluções, a harmonização de convívio vem com essa pré-disposição de trabalhar em cima das convergências e não em cima das divergências, tu consegue estabelecer um bom termo nas negociações, mas não existe forma mágica disso, existe a ação concreta, exemplar, coerente, digna, ética e moral [...]". COMITÉ DE BACIA

"Cuidar não poluindo, trazendo os resíduos de volta, não largando coisas, porque tem gente que arruma o barco, troca o óleo e atira ele dentro da água, a gente aqui cuida muito para que isso não aconteça [...]. O porto deve cuidar do entorno de onde ele fica e eu acho que isso tá acontecendo um pouco aqui agora [...]. Expandir no sentido de ampliar a movimentação de cargas seria ótimo, muito bom mesmo, é normal, quanto mais atividade portuária tiver melhor. Mas nós temos uma preocupação, porque a gente aqui está no meio do porto, porque o porto é aqui e ali, então é uma coisa que preocupa, apesar de que o nosso clube tem mais de 100 anos, mas a gente tá dentro da área, então sempre existe essa preocupação, se ele começar a crescer muito fisicamente, aí é complicado". CLUBE NÁUTICO 


\section{CIDESPORT/2019}

Congresso Internacional

de Desempenho Portuário

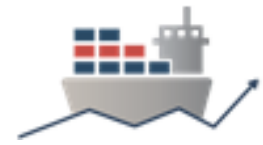

"Os órgãos ambientais e demais instituições públicas e privadas, poderiam capacitar, orientar e conscientizar os pescadores em função do descarte de lixo na água [...]. Dentro do seu limite o porto deve cuidar da cidade e preservar. Ter programas voltados para o meio ambiente e criar um programa ambiental junto aos pescadores [...]. Se crescer vai atrapalhar, tem alguns lugares que a gente bota as redes dentro do São Gonçalo e se ele for expandir estaria invadindo o território de pesca, é ruim, é preocupante". PESCADOR

"Se unindo, criando redes, criando formas de juntarem os talentos, as qualidades, porque hoje um dos problemas que a gente tem é a falta de fiscalização, então a população se torna uma ferramenta fiscalizadora, então se os pesquisadores, os educadores ambientais e a comunidade se unirem, se tornam um observador da natureza e um crítico. E se a gente tomar atitudes unidos, de forma coletiva, a força política que a gente tem é muito maior [...]. O porto tem que investir na educação ambiental da comunidade, promover ações estruturais de fiscalização e de pesquisa, que ajudam a gerar uma rede de ações e informação para poder preservar os recursos hídricos. Tem que incluir comunidade, recurso hídrico e gerar a economia, mas de forma a manter o local preservado [...]. Tem que cuidar da cidade, a gente pode pegar aonde que o porto tá e criar uma zona de amortecimento, um círculo da área de influência que inclui natureza, natureza intocada e natureza urbana. O porto pode ser um espaço cultural absurdo, como já é, só que, às vezes, isso não se expande por causa da violência, eu vejo muitas pessoas fugindo do Porto, pois não se sentem mais seguras lá, eu acho que o Porto de Pelotas junto com a prefeitura e com a comunidade, tem que trabalhar a questão da violência, acho que isso pode ser um legado que ele pode trazer para ali, ajudar a mitigar a violência [...]. Para eles cresceram ali tem que ter participação da comunidade, tem que ser um projeto sustentável, para fazer um projeto modelo, revitalizar e gerar a oportunidade ali, eu ficaria muito feliz por crescer nesse modo, mas de preferência para o lado urbano e não para o lado do banhado, vou deixar bem claro que para o lado do banhado eu não acho uma alternativa legal, eu acho que tem que aproveitar as áreas que já estão impactadas, para o lado do banhado eu ficaria muito preocupado, mesmo licenciando. O aumento do movimento também é uma atividade impactante que tem que ser monitorada e licenciada, ter compensações e mitigações ambientais [...]". CONSERVAÇÃO NÃOGOVERNAMENTAL

"Através de diálogo, usando ferramentas de educação ambiental, espera-se que as ONG's atuem dentro de uma questão social, buscando diálogo e divulgação, mas com sensibilização, se empenhar para gerar a sensibilização e não focar só na denúncia, denunciar é muito fácil, mas educar é uma coisa bastante difícil, então as pessoas que trabalham nessas atividades de pesquisas e de proteção ambiental poderiam ajudar a educar a população, com projetos de educação ambiental de diferentes formas, com informação e dignidade, mostrando o direito que eles têm com o meio ambiente preservado, que tá na Constituição esse direito, então empoderar eles com isso seria o mais importante, talvez o mais difícil, mas o mais efetivo, pois caso contrário, sem as pessoas terem uma noção do que elas merecem e precisam para ter qualidade de vida e do quanto esse ambiente preservado é importante para essa qualidade de vida, elas não têm 


\section{CIDESPORT/2019}

Congresso Internacional

de Desempenho Portuário

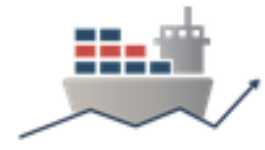

esse conhecimento e não cobram e nem cuidam [...]. Em parte o porto também pode ajudar na educação ambiental, ter programas de educação ambiental portuária [...]. E da cidade cuidar talvez dentro da parte que Ihe caiba, não é cuidar de toda a cidade, mas do entorno, isso não se pode negar, tem que ter noção do que é o impacto de vizinhança e diminuir ele, é cuidar de algumas quadras da zona legalmente definida. Eventualmente pode até gerar alguma coisa para a cidade como um todo, pode até fazer um parque ou investir em uma medida compensatória, pode até ajudar a criar uma unidade de conservação [...]". CONSERVAÇÃO NÃO-GOVERNAMENTAL

Outros tópicos de grandes interesses, tais como a "melhoria na sinalização hidroviária" (convergiram 10 atores), o "gerenciamento ambiental da dragagem" (convergiram 8 atores), a "manutenção da profundidade da hidrovia" (convergiram 7 atores) e a "disposição adequada do material dragado" (convergiram 6 atores), também foram expostos pelos atores. Estes aparecem quando, entre outras perguntas, indagou-se sobre a percepção sobre a profundidade do canal de navegação da hidrovia, a visão sobre a atividade de dragagem e também sobre serviços que o porto poderia oferecer. Todos estes tópicos se relacionam com o tema segurança da navegação, mostrando que esta também é uma zona de convergência forte de ser trabalhada, pois possui tópicos de interesses com alto potencial para construir soluções que ofereçam ganhos também para outros atores usuários ou não do sistema hidroviário - a exemplo da pesca e náutica de recreio (usuários) e órgão ambiental e ONG's (não usuários). Tais interesses podem ser observados, por exemplo, nas seguintes declarações:

"Gostaria de ter sinalização de boias do canal, pois ter o canal sinalizado tem segurança e a navegação fica bem melhor [...]. Há lugares que a profundidade é horrivel, é baixo, a gente tem uma noção mais ou menos quando larga a rede e dá para perceber vendo as grandes embarcações, tem lugares que elas passam e a gente nota que a hélice joga barro para cima, que vai fazer uma manobra, uma curva e se tiver uma croa ou assoreado ela vai encalhar, isso é um sinal que precisa de uma nova dragagem. É normal dragar, é importante para a navegação [...]". ASSOCIAÇÃO COMUNITÁRIA

"A questão da sinalização, a sinalização da lagoa tá muito ruim, a lagoa tá muito mal sinalizada, tem que mudar o sistema de quem responde por isso. [...]. Eu não sei se teria como privatizar a sinalização da lagoa, ou se a Marinha tem que assumir, mas do jeito que tá não dá, tá muito ruim [...]. Para nós a profundidade é boa, mas para as embarcações mercantes já tinha que ser mais profundo e o canal mais largo, porque reduziram a largura do canal para baratear a dragagem, o canal tinha 80 metros de largura e acho que agora tá com 60 metros o canal dragado. A dragagem tem que ser feita com critérios, como era feita aqui antigamente, hoje a draga tira areia de dentro do canal navegável e vai acumulando montículos de areia na lagoa em lugares não demarcados, não sei se isso não vai gerar um banco de areia onde não tem, antigamente colocavam o material em um determinado lugar que se sabia que estava ali, criavam um depósito de areia, hoje a gente não sabe onde fica o material dragado, o que causa certa preocupação". CLUBE NÁUTICO 


\section{CIDESPORT/2019}

Congresso Internacional

de Desempenho Portuário

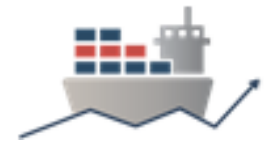

"Melhor sinalização. A profundidade precisa ser melhorada em alguns trechos. A dragagem de hidrovias e portos é uma necessidade e prática mundial. Existem muitas possibilidades técnicas de como fazer - importante é ter plano de controle e estar bem definido a forma e local de descarte do material dragado". OPERADORA PORTUÁRIA

"A dragagem aqui no Canal São Gonçalo preocupa, não parece haver uma preocupação com o período de reprodução das espécies. Ela gera uma grande movimentação de sedimentos e acaba aparecendo lama na lagoa. E a deposição do material dragado é feita na própria lagoa e acaba, às vezes, impossibilitando alguns pesqueiros". PESQUISADOR

"Um aterro hidráulico para dar destino do material dragado, do sedimento dragado, que via de regra se coloca dentro da água mesmo, então vai acabar voltando para o lugar, se tem alguma coisa contaminada tu vai justamente largar de novo dentro da água e eu já localizei junto ao pessoal do porto duas áreas potenciais, para que numa próxima dragagem a gente fizesse um aterro hidráulico, que lá pelas tantas se o material é bom, que me parece que é, pois não aparecem contaminantes que nos preocupe, poderia gerar material para aterro até para a própria prefeitura. Quanto mais eles conseguirem dar cabo nos resíduos das dragagens, para a minha atividade vai ser muito melhor, porque dentro do processo de licenciamento a gente já poderia automaticamente já destinar, já saber para onde é que vai esse sedimento". CONSERVAÇÃO GOVERNAMENTAL

Diante do disposto, foi possível confirmar o quanto é importante a elaboração de uma Agenda Ambiental Local, uma vez que esta pode gerar uma série de oportunidades, pois além de promover a gestão ambiental portuária, esta agenda propicia o relacionamento entre os atores (stakeholders), tais como pescadores, velejadores, lancheiros, navegadores em geral, ONG's, comunidade local, universidades, órgãos ambientais, agências ambientais, governo local, trabalhadores portuários, operadores portuários, autoridade portuária, entre outros. E possibilita ainda, a aproximação destes atores com os procedimentos na prática de gestão da atividade portuária.

\section{CONSIDERAÇÕES FINAIS}

O presente trabalho construiu um escopo de base para a visualização de uma Zona de Possíveis Acordos (ZOPA), que orienta a estruturação da pauta inicial de um provável diálogo para geração de uma Agenda Ambiental Local para o Porto de Pelotas. A ZOPA se constitui em um instrumento facilitador aos debates, uma vez que, esta ferramenta da pré-agenda se apresenta por meio das convergências dos tópicos de interesses, sondados a partir da visão de 20 atores estratégicos (stakeholders) à gestão do porto, sendo possível avaliar como o porto vem sendo percebido por estes atores. Para a construção desta ZOPA, seguiu-se o modelo da abordagem dos ganhos mútuos (Método Harvard de Negociação), também utilizado na elaboração da Agenda Ambiental Local do Porto de Santos.

É fundamental contar com uma pauta adequada para a facilitação da discussão de uma Agenda Ambiental Local, na qual os tópicos devem representar o reconhecimento dos temas onde há convergências, quanto a sua inclusão nos 


\section{CIDESPORT/2019}

Congresso Internacional

de Desempenho Portuário

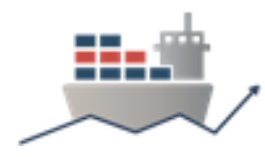

debates e quanto ao sentido em que esses debates devem ser conduzidos. O estudo dos interesses manifestados dá base a uma visão otimista sobre a construção de uma Agenda Ambiental Local como uma articulação de esforços e compromissos públicos capazes de impulsionar uma mudança no padrão técnico do Porto de Pelotas, por meio de um calendário de atividades e resultados que o público possa acompanhar.

A gestão ambiental portuária depende de investimentos e da implantação de equipes dedicadas. A obtenção de financiamentos para viabilizar tais iniciativas pode receber um importante impulso caso a Autoridade Portuária venha a dispor de legitimação pública para seus planos de gestão, resultante do processo de construção de uma Agenda Ambiental Portuária.

Processos como a Agenda Ambiental Local reconhecem o papel da ética e da influência dos diversos atores para a mudança de padrão de desempenho socioambiental das grandes operações econômicas, abrindo canais para que a energia da participação impulsione a qualificação do processo de desenvolvimento. Pelo lado das Autoridades Portuárias e dos negócios portuários, esta agenda é o reconhecimento do espaço legítimo dos demais atores, em suas lógicas próprias de utilização dos recursos e espaços de mútua influência.

Um novo equilíbrio na utilização dos recursos da zona costeira fica mais próximo caso a sociedade encontre caminhos que atendam as diferentes demandas e prioridades que cada ator social traga a uma arena de discussões. Por esse caminho se pode pensar em superar uma lógica negativa do crescimento econômico, pautado pela predominância das decisões de um segmento econômico em relação aos outros interesses, no que se refere às mudanças do ambiente. Ambientes de diálogo podem oferecer alternativas mais sábias, democráticas e inclusivas, caso produzam um alto padrão técnico mais prudente em relação aos desdobramentos ecológicos da atividade econômica.

O crescimento econômico do Porto de Pelotas pode ser bem administrado do ponto de vista socioambiental, caso o porto entenda essa possibilidade como um valor agregado à imagem concorrencial de sua atividade, então a Autoridade Portuária poderá cogitar de trazer seu padrão de gestão ambiental para o nível de um valor estratégico de negócio. Considerando essa possibilidade, investir energia na construção da Agenda Ambiental Local é uma etapa essencial. Mapear e gerenciar com respeito e consideração as partes interessadas (stakeholders) também permite visualizar o complexo e diversificado leque de relações do porto com os demais usuários dos recursos comuns do território.

\section{REFERÊNCIAS}

ANTAQ - Agência Nacional de Transportes Aquaviários. Agendas Ambientais Portuárias - Série Cartilhas Ambientais, 2011. Disponível em:

<http://www.antaq.gov.br/Portal/pdf/CARTILHAAgendasAmbientaisPortuarias.pdf>. Acesso em: mar. 2017.

Baldin, N.; Munhoz, E.M.B. Educação ambiental comunitária: uma experiência com a técnica de pesquisa snowball (bola de neve). Revista Eletrônica do Mestrado em Educação Ambiental, 27(2), 46-60, 2011. Disponível em:

https://www.seer.furg.br/remea/article/view/3193

Campêlo, M. R.; Duhá, P. A. D. Navegação: A história do transporte hidroviário interior no Rio Grande do Sul. Porto Alegre: Centhury, 2009. 


\section{CIDESPORT/2019}

Congresso Internacional

de Desempenho Portuário

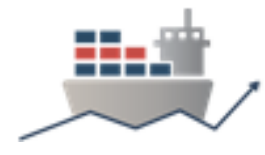

Cicin-Sain, B.; Knecht, R. Integrated Coastal and Ocean Management: Concepts and Practices. Washington: Island Press, 1998.

CIRM - Comissão Interministerial para os Recursos do Mar. Agenda Ambiental Portuária, 1998. Disponível em:

$<$ http://www.antaq.gov.br/portal/pdf/MeioAmbiente/AgendaAmbiental.pdf>. Acesso em: fev. 2017.

Cunha, I. A. Política Ambiental, Negociação de Conflitos e Sustentabilidade. Santos: Editora Universitária Leopoldianum, 2008.

Cunha, I. A. (Org.). Agenda Ambiental do Porto de Santos. Santos: Editora Universitária Leopoldianum, 2014.

Diegues, A. C. Ecologia Humana e Planejamento Costeiro. São Paulo: NUPAUBUSP, 2. ed., 2001.

Fisher, R.; Ertel, D. Estratégias de Negociação: Um guia passo a passo para chegar ao sucesso em qualquer situação. Rio de Janeiro: Ediouro, 1997.

Fisher, R.; Ury, W.; Patton, B. Como Chegar ao Sim: Como negociar acordos sem fazer concessões. Rio de Janeiro: Solomon Editores, 2014.

Freeman, R. E. Strategic Management: a stakeholder approach. Boston: Pitman, 1984.

Gil, A. C. Métodos e Técnicas de Pesquisa Social. São Paulo: Atlas, 6. ed., 2008.

Granja, S. I. B. Manual de Mediação de Conflitos Socioambientais. São Paulo: 5 Elementos Instituto de Educação e Pesquisa Ambiental: UMAPAZ - Universidade Aberta do Meio Ambiente e da Cultura de Paz, 1. ed., 2012.

LABTRANS - Laboratório de Transportes e Logística - Universidade Federal de Santa Catarina. Plano Mestre - Porto de Pelotas, 2013. Disponível em: $<$ http://www.portosdobrasil.gov.br/assuntos-1/pnpl/arquivos/planos-mestressumarios-executivos/se23.pdf>. Acesso em: jun. 2017.

Little, P. E. Os conflitos socioambientais: um campo de estudo e de ação política. In: Bursztyn, M. (Org.). A difícil sustentabilidade: política energética e conflitos ambientais. Rio de Janeiro: Garamond Ltda., p. 107-122, 2001.

Magalhães, T. Operações no Porto vão quadriplicar. Prefeitura de Pelotas. Pelotas, 06 de outubro de 2016. Disponível em:

$<$ http://www.pelotas.rs.gov.br/noticias/detalhe.php?controle=MjAxNi0xMCOwNg==\&c odnoticia=43072>. Acesso em: jun. 2017.

Mazza, G. Testes operacionais prosseguem no Porto de Pelotas com o carregamento da primeira barcaça de madeira. Satolep Press. Pelotas, 11 de outubro de 2016. Disponível em: 


\section{CIDESPORT/2019}

Congresso Internacional

de Desempenho Portuário

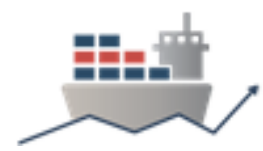

$<$ https://satoleppress.wordpress.com/2016/10/11/testes-operacionais-prosseguemno-porto-de-pelotas-com-o-carregamento-da-primeira-barcaca-de-madeira/>. Acesso em: jul. 2017.

Minayo, M. C. de S. (Org.). Pesquisa Social: teoria, método e criatividade. Petrópolis: Vozes, 21. ed., 2002.

MMA - Ministério do Meio Ambiente, dos Recursos Hídricos e da Amazônia Legal. Os 25 anos do Gerenciamento Costeiro no Brasil: Plano Nacional de Gerenciamento Costeiro (PNGC), 2014. Disponível em: <http://www.mma.gov.br/gestaoterritorial/gerenciamento-costeiro/publica\%C3\%A7\%C3\%B5es>. Acesso em: abr. 2017.

MMA - Ministério do Meio Ambiente, dos Recursos Hídricos e da Amazônia Legal. Agenda Ambiental Portuária, 2016. Disponível em:

<http://www.mma.gov.br/legislacao/item/8539-sistema-de-modelagem-costeira>. Acesso em: mar. 2017.

Polette, M.; Asmus, M. L. Meio ambiente marinho e impactos antrópicos. In: Castello, J. P.; Krug, L. C. (Orgs.). Introdução às Ciências do Mar. Pelotas: Textos, p. 500521, 2015.

PON. Program on Negotiation at Harvard Law School. Welcome to the Program on Negotiation. Cambridge, 2017. Disponível em:

<https://www.pon.harvard.edu/about/>. Acesso em: ago. 2017.

Ross, R. Celulose dá novos contornos à região do Porto de Pelotas. Diário Popular. Pelotas, 10 de outubro de 2016. Disponível em:

$<$ https://www.diariopopular.com.br/index.php?n_sistema=3056\&id_noticia=MTE3NzA w\&id_area=NQ==>. Acesso em: jul. 2017.

Vinha, V. As empresas e o desenvolvimento sustentável: a trajetória da construção de uma convenção. In: May, P. (Org.). Economia do meio ambiente: teoria e prática. Rio de Janeiro: Campus, 2. ed., p.181-204, 2010. 